\title{
Hearts and hands as the starting point
}

\author{
Lewis B. Holmes, MD'
}

\begin{abstract}
PRELUDE
During my internship at Massachusetts General Hospital (1963-1964), while on-call every other night and every other weekend, I had time to read articles in the hospital library in my new field of pediatrics. One winter weekend, I read in Acta Paediatrica Scandinavia a report of the third and fourth individuals with a heritable pattern of malformations of the heart and hands, a "new" disorder described initially by Holt and Oram in 1960. This was an epiphany: a few weeks earlier I had cared for an infant with heart failure due to a large ventricular septal defect and finger-like thumbs; he had similarly affected siblings and a father with an absent thumb on one hand, a small finger-like thumb on the other, and a ventricular septal defect that had closed spontaneously. In this, my first family study, I had financial support (for laboratory studies) and enthusiastic encouragement from John D. Crawford, chief of Pediatric Endocrinology. When I contacted senior cardiologists, one told me about another family with the same phenotype. Now, I could report two families with several affected individuals.
\end{abstract}

Acceptance of my article ${ }^{1}$ for publication several months later was exhilarating. It made the study of the causes of malformations a new focus for me. However, there were no relevant research fellowships. So, instead, I completed an endocrinology fellowship with Dr Crawford for my third year of residency training. I learned how to conduct clinical research projects, such as a study of children who had grown normally with no measurable growth hormone after the surgical removal of a craniopharyngioma. ${ }^{2}$ During this same period, I also collaborated in reporting the first children diagnosed with isovaleric acidemia, a "new" inborn error of metabolism. ${ }^{3}$ I became fascinated by the possibility that there were "inborn errors of morphogenesis" as well. ${ }^{4,5}$ For the last six months of my fellowship year, Dr Crawford allowed me to create my own mini-fellowship in "genetics," a new subspecialty. I scheduled weekly ward rounds with experts in metabolism (Mary Efron) and cytogenetics (Leonard Atkins) and carried out clinical research projects with each of them.

While I was away for two years of required military service, John W. Littlefield established the Genetics Unit in the Department of Pediatrics at Massachusetts General Hospital. He invited me to return as director of Clinical Genetics and to mentor the new genetics fellows, the first of whom was Vincent
M. Riccardi in 1968. In addition, Hugo Moser asked me to complete an encyclopedic compendium of the causes of mental retardation that were associated with physical abnormalities ${ }^{6}$ that he and several colleagues had begun. During three years of writing summaries and requesting published photographs depicting similar cases, I frequently saw discrepancies between the physical features apparent in the photographs and the features listed in the published figure legends. As a result, I decided to study normal physical features in order to clarify terminology, determine frequency, and develop measurements that would provide objectivity.

\section{PROGRESS}

For this project, I focused on newborns in the Harvard maternity service at Boston Lying-In Hospital (BLI), where I could identify and assess all of the minor anomalies, birth marks, and malformations in that population, including those in stillborn fetuses and spontaneous abortions. Again, I benefited from the generous support of the senior faculty, this time in Neonatology (Will Cochran) and Pathology (Shirley Driscoll). Developing this project was my introduction to the challenges in clinical studies: raising funds to hire crucial staff members; developing the study design and forms for gathering and analyzing data consistently; defining the terms to be used; and selecting the relevant technology (e.g., the calipers, rulers, tape measures, and camera). ${ }^{7}$

In addition to examining a systematic series of 7,157 infants, ${ }^{8}$ we began to identify and learn about the common "major" malformations. I had begun this project with a special interest in anencephaly because I had seen an affected newborn in the first delivery I had attended before entering medical school. I became intrigued with the fact that several types of neural tube defects had been identified. In a retrospective review, we had identified infants with the Meckel syndrome, which included occipital encephalocele, absence of premaxilla, polydactyly, and renal anomalies. Our findings showed it was hereditary, probably an autosomal recessive disorder. Yet I learned that the senior epidemiologists studying infants with neural tube defects at BLI had grouped infants with the Meckel syndrome with infants having isolated myelomeningocele or anencephaly. This experience led to an attempt to clarify "the etiologic heterogeneity of neural tube defects." We continued that focus on etiologic and

${ }^{1}$ Medical Genetics Unit, MassGeneral Hospital for Children, Boston, Massachusetts, USA. Correspondence: Lewis B. Holmes (Holmes.Lewis@mgh.harvard.edu) 
phenotypic heterogeneity of common malformations as part of the Active Malformations Surveillance Program at BLI (later a part of Brigham and Women's Hospital). This project lasted 40 years (1972-2012), with many of the findings presented recently in the book, Common Malformations. ${ }^{9}$

The 7,157 newborns we examined included several who had been exposed during pregnancy to postulated human teratogens, including the hormone pregnancy test, anticonvulsant drugs, warfarin, intrauterine contraceptive devices, and maternal diabetes. We thought that our methodology for "systematic surface examinations" would be helpful in evaluating the exposed infants. Subsequently, we also examined infants with early exposures to misoprostol, alcohol, or chorionic villus sampling. These clinical studies showed that details matter: definitions, measurements, masked examiners, and an unexposed comparison group were essential to an informative study design. ${ }^{10}$ During this period at BLI, we realized that fetal exposure to anticonvulsant drugs and maternal diabetes were the two potential teratogens that we would be able to study with adequate statistical power. The Surveillance Program was suspended in 1975 because the office space was no longer available.,

\section{SUCCESS}

In 1979, we were invited back to BLI to continue the Active Malformations Surveillance Program. However, because there was inadequate funding, we continued with a "shoestring" budget and the generous help of volunteers and research fellows. For almost three years during this period, my income came primarily from moonlighting - while I submitted grant proposals. The breakthrough was three years of funding by the manufacturer to study the fetal effects of Bendectin, a popular formulation to treat nausea and vomiting during pregnancy. Fortunately, the company honored its commitment even after the drug was taken off the market. Subsequently, the Diabetes in Early Pregnancy Study, funded by the National Institute of Child Health and Human Development, began. This multicenter project enabled us to use the "systematic surface examinations" to identify major and minor anomalies in newborns born either to women with insulin-dependent diabetes mellitus or to an unexposed comparison group. This project showed me that a team of investigators, including epidemiologists, biostatisticians, and clinicians, was essential for a study to be efficient and insightful.

Meanwhile, with limited support from private foundations, we carried out pilot studies with infants and children who had been exposed to anticonvulsant drugs during pregnancy. Our developing expertise and related publications helped us to obtain National Institutes of Health funding to study all newborns at five Boston area hospitals whose mothers had used an anticonvulsant drug for any reason during pregnancy. ${ }^{10}$ One significant finding was that the infants of mothers who had a history of epilepsy but had used no anticonvulsant drugs in pregnancy were not different from the infants in the unexposed comparison group. Subsequent studies have shown that the severity of the mother's epilepsy was not a confounding factor in the infant's phenotype.
By the 1990s, our "soft money" finances had become more stable and predictable with the creation of the North American AED (antiepileptic drug) Pregnancy Registry (funded by several manufacturers) and funding for the Surveillance Program from the Centers for Disease Control and Prevention in Atlanta. Additional support came from the reintroduction of obstetrics at Massachusetts General Hospital, where I was the staff geneticist in the Prenatal Diagnosis Center.

\section{DENOUEMENT}

In the 1970s and 1980s, there was a stated and unstated attitude in academic medicine that real research occurred in laboratories, not in clinical studies. Physicians were needed primarily to see patients; this was important, but not comparable to the expertise of a laboratory investigator. I have been pleased to see in recent years more respect and support for clinical research.

We ended the Active Malformations Surveillance Program in 2012, and we are now tabulating and analyzing the data derived since 1972. Maybe someday a comparison can be made by a future research group regarding the malformations identified in, for example, 2052-2092 and those we identified in 19722012. The number of specific diagnoses will have increased significantly, reflecting continued improvement in diagnostic technology. In addition, we are now beginning a study of the genetic basis for the teratogenicity of anticonvulsant drugs, using exomic sequencing in parent-child trios. It will be several years before these studies produce definitive results.

Looking back, I see that my clinical research career was possible for several reasons: a supportive and understanding wife; personal commitment of enough time to develop and carry out coherent studies; collaborations with colleagues in varied disciplines (biostatistics, epidemiology, pathology, orthodontics, and clinical teratology); an environment in which research was encouraged; and staying in the same place. The latter-the same place-was essential for my two major projects of identifying causes of malformations in general and determining the fetal effects of anticonvulsant drugs. Opportunities at other institutions never looked more attractive than the promise of continuing the projects under way in Boston.

I also made many mistakes. The most common was trying to do too much. For example, I tried my hand at experimental teratology, which I enjoyed but began when my plate was already "too full." I would have benefited from being part of a larger research group and from having a mentor who kept saying to me, "Focus, focus."

\section{DISCLOSURE}

The author declares no conflict of interest.

\section{REFERENCES}

1. Holmes LB. Congenital heart disease and upper-extremity deformities: a report of two families. N Engl J Med 1965;272:437-444

2. Holmes LB, Frantz AG, Rabkin MT, Soeldner JS, Crawford JD. Normal growth with subnormal growth-hormone levels. N Engl J Med 1968;279:559-566.

3. Budd MA, Tanaka K, Holmes LB, Efron ML, Crawford JD, Isselbacher KJ. Isovaleric acidemia. Clinical features of a new genetic defect of leucine metabolism. N Engl J Med 1967;277:321-327. 
4. Holmes LB. Inborn errors of morphogenesis: a review of hereditary localized malformations. N Engl J Med 1974;291:763-773.

5. Nelson K, Holmes LB. Malformations due to presumed spontaneous mutations in newborn infants. N Eng/ J Med 1989;320:19-23.

6. Holmes LB, Moser HW, Halldorsson TS, Mack C, Pant SS, Matzilevich BJ. Mental Retardation: An Atlas of Diseases with Associated Physical Abnormalities. Macmillan: New York, 1972.
7. Leppig KA, Werler MM, Cann Cl, Cook CA, Holmes LB. Predictive value of minor anomalies. I. Association with major malformations. J Pediatr 1987;110:531-537.

8. Holmes LB, Driscoll SG, Atkins L. Etiologic heterogeneity of neural-tube defects. NEngl J Med 1976;294:365-369.

9. Holmes LB. Common Malformations. Oxford University Press: New York, 2012.

10. Holmes LB, Harvey EA, Coull BA, et al. The teratogenicity of anticonvulsant drugs. N Eng/ J Med 2001;344:1132-1138. 